\title{
Plasma concentrations of zinc, copper, interleukin-6 and interferon- $\gamma$, and plasma dipeptidyl peptidase IV activity in chronic hepatitis $\mathbf{C}$
}

\author{
KURT GRÜNGREIFF ${ }^{1}$, THOMAS HEBELL ${ }^{2}$, KAI GUTENSOHN ${ }^{2}$, \\ ANNEGRET REINHOLD ${ }^{3}$ and DIRK REINHOLD ${ }^{3}$ \\ ${ }^{1}$ Heydeckstrasse 9, 39104 Magdeburg; ${ }^{2}$ Laboratory Dr Wagner, Werner-von-Siemens-Strasse 10, 37077 Göttingen; \\ ${ }^{3}$ Institute of Molecular and Clinical Immunology, Otto-von-Guericke-University Magdeburg, \\ Leipziger Strasse 44, 39120 Magdeburg, Germany
}

Received September 16, 2008; Accepted October 2, 2008

DOI: 10.3892/mmr_00000062

\begin{abstract}
Copper and zinc are essential trace elements which play an important role in various biological processes. Along with various cytokines, glucocorticoids, glucagon and insulin, the acute-phase protein metallothionein is involved in the regulation of immune cell functions. Metallothionein is the central protein regulating zinc concentration. Zinc deficiency is often found in patients with chronic liver disease, chronic kidney disease and diabetes mellitus, and in those with acute infectious diseases. In contrast, copper deficiency is rarely reported. In order to determine whether there is a correlation between zinc and/or copper and selected immunological parameters in patients with chronic liver disease, we investigated plasma levels of zinc and copper, concentrations of interleukin-6 (IL-6) and interferon- $\gamma$ (IFN- $\gamma$ ), and the enzymatic activity of dipeptidyl peptidase IV (DP IV, CD26) in patients with chronic hepatitis $\mathrm{C}$ and in healthy control subjects. Whereas zinc plasma levels did not differ between patients and control subjects, copper concentrations revealed gender-specific differences. The mean copper concentration was higher in female patients with chronic hepatitis $\mathrm{C}$ and in female controls compared with the respective male groups. The immunological parameters of IFN- $\gamma$ concentration and DP IV activity showed similar levels in the patient and control groups. Of note, the mean IL-6 plasma concentrations were significantly elevated in patients with chronic hepatitis $\mathrm{C}$ compared with healthy control subjects. In summary, there was no correlation between either zinc or copper concentrations and the immunological parameters measured (IL- 6 and IFN- $\gamma$ levels and DP IV activity) in patients with chronic hepatitis C and in healthy control subjects.
\end{abstract}

Correspondence to: Dr Kurt Grüngreiff, Heydeckstrasse 9, 39104 Magdeburg, Germany

E-mail: dr.kgruengreiff@t-online.de

Key words: chronic hepatitis C, zinc copper, interleukin-6, interferon $-\gamma$, dipeptidyl peptidase IV

\section{Introduction}

Zinc and copper are essential trace elements that play an important role in numerous biological processes in humans, animals and plants. Plasma and tissue levels of these trace elements are influenced by stress (1-2), trauma (3) and infection (4-5). Under these conditions, zinc plasma concentrations are normally reduced and copper levels are elevated (6). Similar observations have been reported in the liver tissue of patients with hepatocellular carcinoma (7).

During inflammation, tissue injury and stress, the proinflammatory cytokines interleukin (IL)- 1 and -6 , and tumor necrosis factor $\alpha(\mathrm{TNF}-\alpha)$ are mainly produced by activated macrophages. These mediators in turn induce the synthesis of acute-phase proteins, such as coeruloplasmin and metallothionein, in the liver. Metallothionein is a metal-binding protein that protects against oxidative damage and oxygen metabolites resulting from inflammation and tissue damage (8).

The main zinc metabolism occurs in the liver hepatocytes. There are two storage pools: slow and fast zinc. Metallothionein is the central protein regulating zinc concentration. The regulation of metallothionein synthesis depends not only on cytokine levels, but is also regulated by insulin, glucagon and glucocorticoids. A strong interaction between metallothionein, zinc and copper exists as the two trace elements compete to bind to metallothionein (8).

In addition to the regulation of zinc resorption, distribution and cellular accumulation by metallothionein, zinc uptake itself leads to increased metallothionein synthesis. With the help of tracer studies, it has been revealed that a complete zinc exchange takes two days (8). In patients with zinc deficiency, reduced zinc concentrations in the liver are one of the causes of impaired hepatocyte regeneration.

The pathogenesis of liver cell injury in chronic hepatitis $\mathrm{C}$ infection is poorly understood, and the exact mechanism whereby hepatitis $\mathrm{C}$ virus (HCV) establishes itself and persists remains unclear. Previous studies have demonstrated that $\mathrm{T}$-cell immunoregulatory cytokines contribute to liver damage. Escape mutations by HCV itself, insufficient T-cell response and weak humoral immune responses have been proposed as the main culprits for the chronicity of HCV infection (9-12). 
Recently, Yuasa et al (13) demonstrated that zinc may play an important role as a negative regulator of $\mathrm{HCV}$ replication in genome-length HCV RNA-replicating cells. Thus, zinc supplementation appears to offer a novel approach for future strategies in the treatment of intractable chronic hepatitis $\mathrm{C}$.

Activation of the cellular immune response is implicated in the eradication of $\mathrm{HCV}$ infection. It has been shown that the outcome of HCV infection depends on the Th1/Th2 cytokine balance. Th1 cytokines (IL-2 and IFN- $\gamma$ ) stimulate phagocytemediated immune reactions, whereas Th2 cytokines (IL-4, -5 and -10) stimulate the production of $\operatorname{IgE}$ and eosinophil/ mast-cell-mediated immune reactions, and down-regulate Th1 responses. The Th1 profile appears to be associated with a benign and favorable clinical outcome in HCV infection. A prevalent Th2 response may contribute to the chronicity of $\mathrm{HCV}$ infection and the severity of liver disease (14-15).

In patients with liver cirrhosis and hepatocellular carcinoma, the serum concentration of metallothionein is reduced compared to that of patients with chronic hepatitis and healthy control subjects. In contrast, serum copper levels are significantly elevated in patients with cirrhosis and hepatocellular carcinoma compared with patients with chronic hepatitis and healthy control subjects. Zinc concentration is reduced in all three patient groups compared with control subjects (16).

Dipeptidyl peptidase IV (DP IV, CD26) is a widely expressed transmembrane ectoenzyme that is also present as a soluble form in biological fluids. It has been implicated in T-cell activation, hepatocyte-extracellular matrix interactions and fibroblast proliferation. Elevated levels of soluble DP IV activity have been described in patients with chronic HCV infection (17-19). Moreover, serum DP IV activity has been proposed as an indicator of HCV-induced liver injury (18).

The present study aimed to evaluate concentrations of zinc and copper, as well as those of IL- 6 and IFN- $\gamma$, and plasma DP IV activity in patients with chronic HCV infection and in control subjects who showed no sign of liver disease or infection. In particular, in our investigation of a possible correlation between the levels of trace elements and immunological parameters, differences in measurements between the genders were taken into account.

\section{Patients and methods}

Patients. Fifty patients with native chronic HCV infection were included. The diagnosis of chronic hepatitis $\mathrm{C}$ was based on patient history, physical examination and laboratory findings. In 37 cases, the diagnosis was confirmed by liver biopsy and histological examination. All patients were positive for HCV antibodies and HCV-RNA. The mean ages of females $(n=32)$ and males $(n=18)$ were 57 and 48 years, respectively. Four of the female patients $(12.5 \%)$ had used oral contraceptives.

As controls, $30 \mathrm{HCV}$-antibody-negative subjects were included in the study. These subjects had neither a history of liver or infectious disease, nor clinical or laboratory signs of it. The mean ages of females $(n=23)$ and males $(n=7)$ were 47 and 45 years, respectively. Eight of the female control subjects $(28.7 \%)$ had used oral contraceptives. Patient and control subject characteristics are listed in Table I. Patients and control subjects gave their informed consent to the study. The study protocol was in accordance with the ethical guidelines of the Declaration of Helsinki, 1985.

Zinc and copper measurements. Venous blood was collected in the morning on an empty stomach. Plasma concentrations of zinc and copper were measured using atomic absorption spectroscopy (spectrometer 2100 for zinc and 4100 ZL for copper; both from Perkin Elmer, USA. Reference values were 55-150 $\mu \mathrm{g} / \mathrm{dl}$ for zinc and 74-122 $\mu \mathrm{g} / \mathrm{dl}$ for copper.

Cytokine measurements. The IL-6 and IFN- $\gamma$ concentrations of the plasma samples were determined using commercially available sandwich enzyme-linked immunosorbent assays (high-sensitivity Quantikine HS human IL-6 ELISA and Quantikine human IFN- $\gamma$ ELISA; R\&D Systems, Wiesbaden, Germany) according to the manufacturer's instructions. The sensitivity of the IL-6 ELISA was $<0.11 \mathrm{pg} / \mathrm{ml}$ and that of the IFN- $\gamma$ ELISA $<8 \mathrm{pg} / \mathrm{ml}$. The cut-off values of IL- 6 and IFN- $\gamma$ were $<20 \mathrm{pg} / \mathrm{ml}$.

Measurements of dipeptidyl peptidase IV enzymatic activity. DP IV enzymatic activity was determined in a microplate assay using 1.6 mM Gly-Pro-4-nitroanilide (Gly-Pro-pNA, Bachem, Heidelberg, Germany) and $10 \mu \mathrm{l}$ plasma in the reaction mixture (20). The cut-off value of DP IV activity was $<450 \mathrm{pkat} / \mathrm{ml}$.

Statistics. For statistical analyses, the Excel (Microsoft, Redmond, USA) and Statview 5.0 (SAS Institute Inc., Cary, USA) software programs were used. Data were compared using linear regression analysis. Correlations were calculated using the Spearman rank correlation test. Correlations $\leq-0.7$ or $\geq 0.7$ were considered significant.

Descriptive statistics are shown as the means \pm standard error of the mean (SEM) or as a range (min-max), and P-values are based on the exact permutational distribution of the test statistics rather than being a normal approximation. $\mathrm{P}<0.05$ was considered to be statistically significant. Since the underlying investigations were of an exploratory nature, any kind of $\alpha$ adjustment was omitted.

\section{Results}

Serum zinc concentrations in patients with chronic HCV infection and those in the control group showed no significant differences between men and women, and ranged within normal values (Table II). An analysis of individual patients and control subjects revealed that: a) in 9 patients with chronic $\mathrm{HCV}$ and in 4 healthy subjects, a slight zinc deficiency was found $(<71 \mu \mathrm{g} / \mathrm{dl})$; b) out of 50 patients who were partially followed-up for 9 years, 18 had a zinc deficiency requiring zinc substitution; and c) 4 out of 6 patients with liver cirrhosis exhibited hypozincemia.

In contrast, significant gender-specific differences were observed for plasma copper concentrations. These were significantly higher in the female vs. male control groups $(\mathrm{P}=0.0068)$ as well as in the female vs. male patient groups $(\mathrm{P}=0.0098)$.

As seen in Table II, the highest copper levels were found in the female control group $(159 \pm 7.72 \mu \mathrm{g} / \mathrm{dl})$ followed by 
Table I. Clinical data of patients $(n=50)$ and healthy control subjects with no sign of liver disease or infection $(n=30)$.

Patients with chronic HCV infection

\begin{tabular}{|c|c|c|}
\hline \multicolumn{2}{|l|}{ Women $(n=32)$} & Mean age 57.25 years \\
\hline Men $(n=18)$ & Mea & ge 47.56 years \\
\hline \multicolumn{2}{|c|}{ Stage of chronic HCV infection } & (No.) \\
\hline \multicolumn{2}{|l|}{ Liver cirrhosis } & 6 \\
\hline \multicolumn{2}{|c|}{ Chronic hepatitis without fibrosis } & 17 \\
\hline \multicolumn{2}{|c|}{$\begin{array}{l}\text { Chronic hepatitis with fibrosis } \\
\text { stage 1-3 (Desmet and Scheuer) }\end{array}$} & 20 \\
\hline \multicolumn{2}{|c|}{ No liver histology } & 7 \\
\hline \multicolumn{2}{|c|}{ Additional complaints } & (No.) \\
\hline \multicolumn{2}{|c|}{$\begin{array}{l}\text { Overlap syndrome (chronic hepatitis } \\
\text { plus primary biliary cirrhosis) }\end{array}$} & 2 \\
\hline \multicolumn{2}{|l|}{ Diabetes mellitus } & 5 \\
\hline \multicolumn{2}{|l|}{ Hypothyroidism } & 3 \\
\hline \multicolumn{2}{|l|}{ Hemophilia } & 3 \\
\hline \multicolumn{2}{|l|}{ Rheumatism } & 3 \\
\hline \multicolumn{2}{|l|}{ Prostate cancer } & 1 \\
\hline \multicolumn{2}{|l|}{ Lichen ruber } & 1 \\
\hline \multicolumn{2}{|l|}{ Laboratory data } & Normal range \\
\hline ALAT $(\mu \mathrm{mol} / \mathrm{sl})$ & $0.86 \pm 0.49$ & $0.17-0.58$ \\
\hline $\mathrm{ASAT}(\mu \mathrm{mol} / \mathrm{sl})$ & $0.83 \pm 0.38$ & $0.17-0.58$ \\
\hline GGT $(\mu \mathrm{mol} / \mathrm{sl})$ & $1.07 \pm 0.86$ & $0.58-1.10$ \\
\hline
\end{tabular}

Control subjects

$\begin{array}{lc}\text { Women }(\mathrm{n}=24) & \begin{array}{c}\text { Mean age } 47.00 \text { years } \\ \text { Mean age } 45.33 \text { years }\end{array} \\ \text { Men }(\mathrm{n}=6) & \text { (No.) } \\ \text { Diseases present in controls } & 15 \\ \text { No disease } & 4 \\ \text { Hypothyroidism, subclinical } & 4 \\ \text { Diabetes mellitus } & 4 \\ \text { Chronic gastritis } & 1 \\ \text { Colitis ulcerosa } & 1 \\ \text { Morbus Crohn } & 1 \\ \text { Rheumatism } & \end{array}$

the female patient group $(147 \pm 6.02 \mu \mathrm{g} / \mathrm{dl})$. Conversely, in the male patient group, the mean values for copper were elevated as compared to the male control group $(123 \pm 5.89$ vs. $105 \pm 6.06 \mu \mathrm{g} / \mathrm{dl})$. Notably, mean copper levels in the female control and patient groups were higher than the established reference values of 74-122 $\mu \mathrm{g} / \mathrm{dl}$. The mean copper concentration for the male patients with chronic $\mathrm{HCV}$ infection was only slightly higher than the normal value (122 $\mu \mathrm{g} / \mathrm{dl})$. In 9/32 female patients with chronic hepatitis $\mathrm{C}$ and in $12 / 23$ female control subjects, copper levels $>160 \mu \mathrm{g} / \mathrm{dl}$ were found. The highest copper concentrations, of $225 \mu \mathrm{g} / \mathrm{dl}$, were measured in
Table II. Plasma concentrations of zinc and copper in patients with chronic hepatitis $\mathrm{C}$ and in healthy control subjects with no sign of liver disease or infection. ${ }^{\text {a }}$

\begin{tabular}{|c|c|c|}
\hline Chronic hepatitis C & Female & Male \\
\hline \multicolumn{3}{|l|}{ Zinc } \\
\hline Mean \pm SEM & $84 \pm 2.65$ & $87 \pm 2.83$ \\
\hline Range (min-max) & $46-112$ & $65-108$ \\
\hline \multicolumn{3}{|l|}{ Copper } \\
\hline Mean \pm SEM & $147 \pm 6.02$ & $123 \pm 5.89$ \\
\hline Range (min-max) & $94-255$ & $95-179$ \\
\hline Zinc:copper ratio & 0.57 & 0.71 \\
\hline Healthy control subjects & Female & Male \\
\hline \multicolumn{3}{|l|}{ Zinc } \\
\hline Mean \pm SEM & $88 \pm 2.71$ & $89 \pm 4.16$ \\
\hline Range (min-max) & $58-105$ & $72-101$ \\
\hline \multicolumn{3}{|l|}{ Copper } \\
\hline Mean \pm SEM & $159 \pm 7.72$ & $105 \pm 6.06$ \\
\hline Range (min-max) & $91-227$ & $83-123$ \\
\hline Zinc:copper ratio & 0.55 & 0.85 \\
\hline \multicolumn{3}{|c|}{ 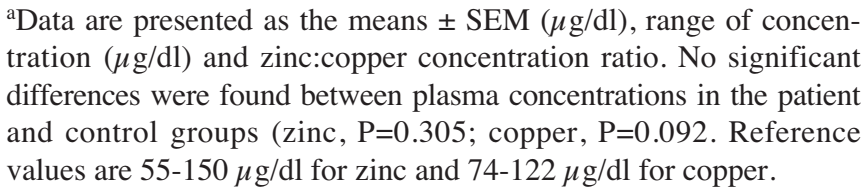 } \\
\hline
\end{tabular}

a female patient with chronic hepatitis C. Of 18 male patients, 4 showed copper levels $>140 \mu \mathrm{g} / \mathrm{dl}$. In the male control group, the highest copper levels measured were $123 \mu \mathrm{g} / \mathrm{dl}$ (Table II).

Taken together, these results suggest that plasma copper concentrations show a gender dependency. This observation was confirmed by calculating the zinc:copper ratio (Table II). There was no difference in the ratio between the female patients and control subjects (0.57 vs. 0.55$)$. In contrast, in the male patient group the ratio was clearly lower than in the male control group (0.71 vs. 0.85$)$.

We further assessed the plasma concentrations of the cytokines IL-6 and IFN- $\gamma$, as well as DP IV activity (Fig. 1). IL-6 plasma concentrations were significantly higher in female and male patients with chronic hepatitis $\mathrm{C}(\mathrm{p}<0.05$; mean $5.5 \pm 1.76$ and $6.4 \pm 3.22 \mathrm{pg} / \mathrm{ml}$, respectively) as compared to the control subjects (female subgroup, mean $1.4 \pm 0.29 \mathrm{pg} / \mathrm{ml}$; male subgroup, mean $2.5 \pm 1.51 \mathrm{pg} / \mathrm{ml}$ ) (Fig. 1A).

In patients with chronic hepatitis $\mathrm{C}$, the concentrations of IFN- $\gamma$ ranged from 3.4 to $13.3 \mathrm{pg} / \mathrm{ml}$ (female patient subgroup, mean $6.0 \mathrm{pg} / \mathrm{ml}$; male patient subgroup, mean $5.5 \mathrm{pg} / \mathrm{ml}$ ). Compared with the patients, healthy control individuals displayed similar levels of IFN- $\gamma$, ranging from 3.0 to $8.6 \mathrm{pg} / \mathrm{ml}$ (female control subgroup, mean $4.7 \mathrm{pg} / \mathrm{ml}$; male control subgroup, mean $5.1 \mathrm{pg} / \mathrm{ml}$ ) (Fig. 1B). 

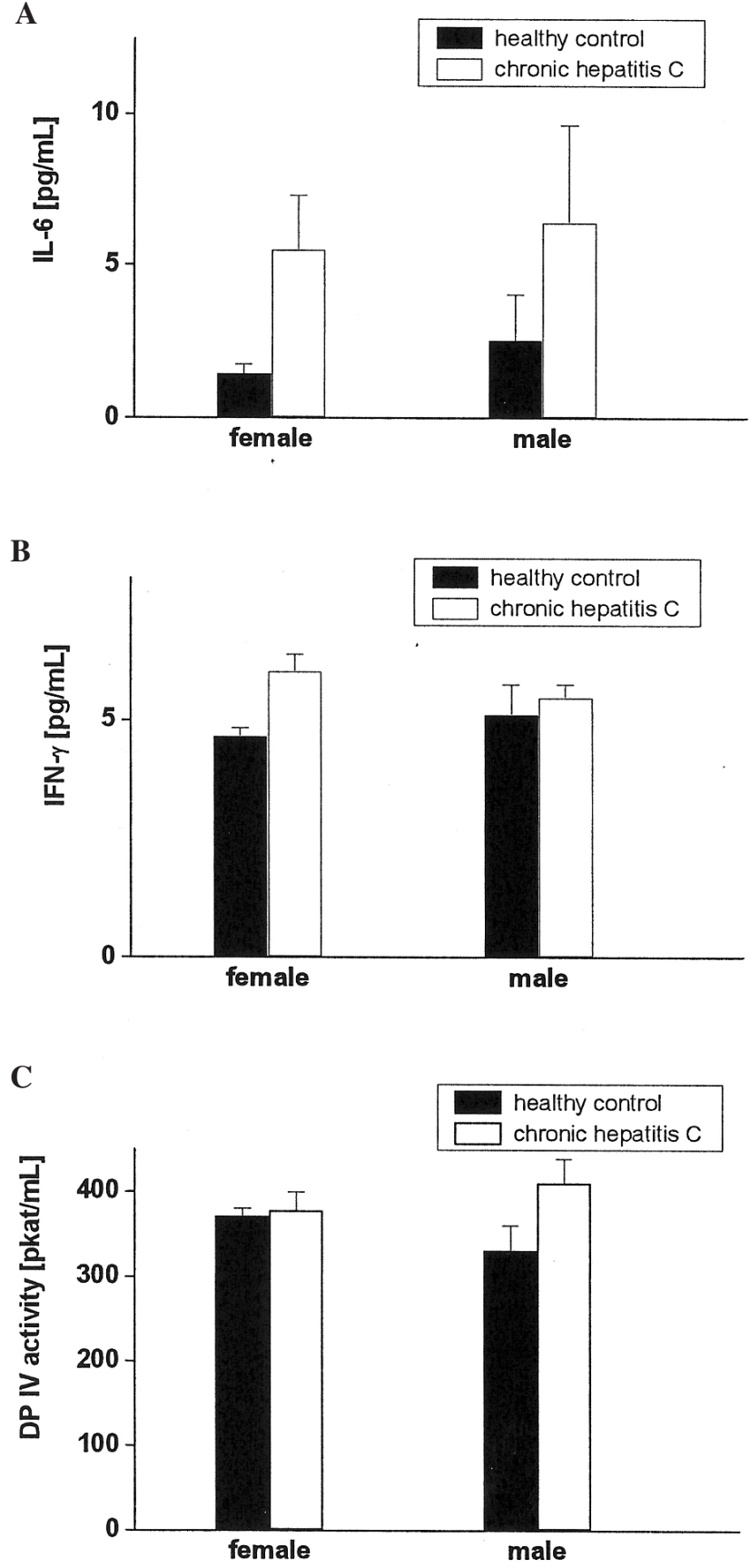

Figure 1. IL-6 and IFN- ${ }_{-\gamma}$ concentrations and DP IV enzymatic activity in the plasma of patients with chronic HCV infection and in healthy control subjects with no sign of liver disease or infection. Data are presented as the means \pm SEM. Significant differences were found between (A) IL-6 plasma concentrations $(\mathrm{P}<0.05)$, but not $(\mathrm{B}) \mathrm{IFN}-\gamma$ plasma concentrations $(\mathrm{P}=0.135)$ or (C) DP IV enzymatic activity $(\mathrm{p}=0.538)$ in the patients and controls.

There were no differences between DP IV enzymatic activity in patients with chronic hepatitis $\mathrm{C}$ (female subgroup, mean $377 \pm 21.94 \mathrm{pkat} / \mathrm{ml}$; male subgroup, mean $410 \pm 28.29 \mathrm{pkat} / \mathrm{ml}$ ) and healthy control individuals (female subgroup, mean $371 \pm 9.34 \mathrm{pkat} / \mathrm{ml}$; male subgroup, mean $330 \pm 29.59 \mathrm{pkat} / \mathrm{ml}$ ) (Fig. 1C).

Moreover, we found no correlations between zinc or copper plasma concentrations and IL- 6 or IFN- $\gamma$ levels or DP IV activity [zero, hypothesis (no correlation) for all possible positive combinations; $\mathrm{p}<0.0001]$.

\section{Discussion}

In order to investigate a possible association between immunological parameters and trace elements, we determined and compared zinc, copper, IL-6 and IFN- $\gamma$ plasma concentrations and DP IV activity in patients with chronic HCV infection and healthy control individuals.

With the exception of IL- 6 concentrations, no differences were found between patients and control subjects. However, a detailed analysis of the two groups according to gender revealed gender-dependent differences for copper but not for zinc levels. The mean plasma values of copper in women were significantly higher in the patient and control groups compared with the values for men. Copper levels were higher in the female control group than in the female patient group, whereas the opposite result was seen in the male groups.

The apparent gender-dependent differences in plasma copper concentrations may be influenced by sex hormones. High copper levels, especially in the female control group, may be caused by hormonal contraception. During pregnancy, which is a hormonal situation similar to that found in contraceptive users, copper concentration increases while zinc levels decrease. It is known that the estrogen-gestagen ratio is behind these changes (21). However, in the present study, differences in copper concentration were not due to contraception only as only $12.5 \%$ of the patients and $28.7 \%$ of the control subjects had used oral hormonal contraception therapy.

Nutrition is another possible explanation for differences in copper concentration. However, in the current study one cannot expect to see clear differences in copper concentration, as the entire study sample lived in the same geographic area. Meat, especially liver, nuts and vegetables contain high concentrations of copper. Copper resorption is inhibited by high doses of vitamin $\mathrm{C}$, while supplementation with ascorbic acid, cysteine and zinc can reduce copper toxicity (22). Harris et al (23) performed a study on 23 post-menopausal women who received an isocaloric diet containing defined copper and zinc concentrations. The authors concluded that although no antagonism exists between zinc and copper, there is interdependence between the two trace elements.

Our results, which show similar zinc and copper concentrations in patients with chronic hepatitis $\mathrm{C}$ and healthy control subjects, are in disagreement with those of Kalkan et al (5), who reported significantly reduced zinc levels and significantly elevated copper levels in patients with chronic hepatitis $\mathrm{B}$ and $\mathrm{C}$ compared with healthy control subjects. Gender-specific zinc and copper concentrations in their study were not calculated, and the differences were attributed to the effect of cytokines and other inflammatory mediators present in chronic hepatitis patients. However, this hypothesis is not supported by experimental data. Barany et al (24) described a positive correlation between zinc and copper in normal human blood and serum, though again no gender-specific analysis of the results was performed. Moscarella et al (25) reported significantly reduced serum zinc levels in patients with decompensated liver cirrhosis, while their copper and manganese concentrations remained unchanged.

Singer et al (26) demonstrated that plasma levels of zinc and copper were reduced in patients who had undergone orthotopic liver transplantation compared to other types of 
major surgery. The low levels of these trace elements persist for up to 5 days after transplantation, despite appropriate supplementation (26). These results once more underline the physiological role of the liver in regulating the zinc and copper metabolism.

Zinc levels depend on the severity of liver disease. In patients with decompensated liver cirrhosis, zinc concentrations are reduced by up to $75 \%$, whereas patients with chronic hepatitis B or C exhibit just moderate reduction (27). This is explained by changes in the protein and amino acid metabolism and by disturbances in intestinal resorption and hepatic zinc extraction, which are less pronounced in chronic hepatitis than in liver cirrhosis. In chronic hepatitis, the effect of proinflammatory cytokines is believed to play an important role in determining trace element concentration.

Similar to our results, Cesur et al (28) reported no significant differences between zinc and copper serum concentrations in patients with chronic hepatitis $\mathrm{C}$ and healthy control subjects. Another finding of our study is the significant increase in IL-6 concentration in patients with chronic hepatitis $\mathrm{C}$. This result is consistent with previously published data and suggests that persistent infection, especially chronic hepatitis, is characterized by an elevated IL- 6 concentration $(29,30)$.

In our study, we did not observe any significant differences between IFN- $\gamma$ concentrations in patients with chronic hepatitis and in control subjects. This observation is confirmed by previous studies, which reported no differences between IFN- $\gamma$ concentrations in $\mathrm{HCV}$-infected patients and in control subjects (31-33). Moreover, we observed no differences in DP IV activity in patients with chronic hepatitis $\mathrm{C}$ compared with control subjects. This result is inconsistent with previously published data showing increased DP IV activity in various liver diseases such as primary biliary cirrhosis (34), cholestasis (35) and chronic hepatitis C (18). Firneisz et al (18) found a strong correlation between DP IV and transaminase activity, and increased DP IV activity has been implicated in hepatocyte damage.

To the best of our knowledge, this is the first study to combine an investigation of trace elements (zinc and copper), cytokines (IL-6 and IFN- $\gamma$ ) and DP IV enzymic activity with special reference to gender differences. In conclusion, not excluding a $\beta$ error, we did not find a correlation between levels of the trace elements zinc and copper and immunological parameters, including IL-6 and IFN- $\gamma$ levels and DP IV activity.

\section{References}

1. Joung H, DiSilvestro RA, Burge JC, Choban PS and Flancbaum L: Zinc and copper-related blood parameters in male trauma patients. Nutr Res 18: 693-701, 1998.

2. Singh A, Smoak BL, Patterson KY, May LG, Veillin C and Deuster PA: Biochemical indices of selected trace minerals in man: effect of stress. Am J Clin Nutr 53: 126-131, 1991.

3. Powanda MC, Villareal Y, Rodriguez E Jr, Braxton G and Kennedy CR: Redistribution of zinc within burned and burned infected rats. Proc Soc Exp Biol Med 163: 296-302, 1980.

4. Shanbhogue LKR and Paterson N: Effect of sepsis and surgery on trace minerals. J Parenter Enteral Nutr 14: 287-290, 1990.

5. Kalkan IA, Bulut V, Avri S, Celik I and Bingol NK: Trace elements in viral hepatitis. J Trace Elem Med Biol 16: 227-230, 2002.

6. Galloway P, McMillan DC and Sattar N: Effect of the inflammatory response on trace element and vitamin status. Ann Clin Biochem 37: 289-297, 2003.
7. Ebara M, Fukuda H, Hatano R, Saisho H, Nagato Y, Suzuki K, Nakajima K, Yukawa M, Kondo F, Nakayama A and Sakurai H: Relationship between copper, zinc and metallothionein in hepatocellular carcinoma and its surrounding liver parenchyma. J Hepatol 33: 415-422, 2000.

8. Cousins RJ: Absorption, transport and hepatic metabolism of copper and zinc: special reference to metallothionein and ceruloplasmin. Physiol Rev 65: 238-309, 1985.

9. Naoumow NV: Hepatitis C virus-specific $\mathrm{CD}^{+} \mathrm{T}$ cells: do they help or damage? Gastroenterology 117: 1012-1014, 1999.

10. Racanelli V and Rehermann B: Hepatitis $C$ virus infection: when silence is deception. Trends Immunol 24: 456-464, 2003.

11. Leroy V, Vigan I, Mosnier JF, Dufeu-Duchesne T, Pernollet M, Zarski JP, Marche PN and Jouvin-Marche E: Phenotypic and functional characterization of intrahepatic $\mathrm{T}$ lymphocytes during chronic hepatitis C. Hepatology 38: 829-841, 2003.

12. Eisen-Vandervelde AL, Yao ZQ and Hahn YS: The molecular basis of $\mathrm{HCV}$-mediated immune dysregulation. Clin Immunol 111: 16-21, 2004.

13. Yuasa K, Naganuma A, Sato K, Ikeda M, Kato N, Takagi H and Mori M: Zinc is a negative regulator of hepatitis $\mathrm{C}$ virus RNA replication. Liver Int 26: 1111-1118, 2006.

14. Napoli J, Biskop GA, McGuiness PH, Painter DM and McCaughan GW: Progressive liver injury in chronic hepatitis C infection correlates with increased intrahepatic expression of Th1-associated cytokines. Hepatology 24: 759-765, 1996.

15. Jacobson Brown PM and Neuman GM: Immunopathogenesis of hepatitis $\mathrm{C}$ viral infection: Th1/Zh2 responses and the role of cytokines. Clin Biochem 34: 167-171, 2001.

16. Nakayama A, Fukuda H, Ebara M, Hamasaki H, Nakajima K and Sakurai HA: New diagnostic method for chronic hepatitis, liver cirrhosis, hepatocellular carcinoma based on serum metallothionein, copper and zinc levels. Biol Pharm Bull 25: 426-431, 2002.

17. Reinhold D, Kähne T, Steinbrecher A, Wrenger S, Neubert K, Ansorge $S$ and Brocke $S$ : The role of dipeptidyl peptidase IV (DP IV) enzymatic activity in T cell activation and autoimmunity. Biol Chem 383: 1133-1138, 2002.

18. Firneisz G, Lakatos PL, Hungarian Viral Hepatitis Study Group and Szalay F: Serum dipeptidyl peptidase (DPPIV, CD26) in chronic hepatitis C. Scand J Gastroenterol 36: 877-890, 2001.

19. Andrieu T, Thibault V, Malet I, Laporte J, Bauvois B, Agut H and Cahour A: Similar increased serum dipeptidyl peptidase IV activity in chronic hepatitis $\mathrm{C}$ and other viral infections. J Clin Virol 27: 59-68, 2003.

20. Schön E, Demth HU, Barth A and Ansorge S: Dipeptidyl peptidase IV of human lymphocytes. Evidence for specific hydrolysis of glycylprolin p-nitroanilide in T-lymphocytes. Biochem J 223: 255-258, 1984.

21. Wischnik A: Zink in Frauenheilkunde und Geburtshilfe. Therapiewoche 42: 172-177, 1992.

22. Persia ME, Parsons CM and Baker DH: Amelioration of oral copper toxicity in chicks by dietary additions of ascorbic acid, cysteine and zinc. Nutr Res 23: 1709-1718.

23. Harris ED: Zinc and copper: evidence for interdependence, not antagonism. Nutrition 17: 734, 2001.

24. Barany E, Bergdahl IA, Bratteby LE, Lundh T, Samuelson G, Schütz A, Skerfving S and Oskarsson A: Relationships between trace element concentrations in human blood and serum. Toxicol Lett 134: 1777-1784, 2002.

25. Moscarella S, Duchini A and Buzzelli G: Lipoperoxidation, trace elements and vitamin $\mathrm{E}$ in patients with liver cirrhosis. Eur J Gastroent Hepatol 6: 633-636, 1994.

26. Singer P, Kogan A, Broza I, Diamond E, Zinder O and Cohen J: Plasma zinc and copper concentrations after orthotopic liver transplantation. Transplant Proc 32: 701, 2000.

27. Grüngreiff K: Zinc in liver disease. J Trace Elem Exp Med 15: 67-78, 2002.

28. Cesur S, Cebeci SA, Kavas GO, Yilmaz N and Buyukkagnici DI: Serum copper and zinc concentrations in patients with chronic hepatitis C. J Infect 51: 35-37, 2005.

29. Grüngreiff K, Reinhold D and Ansorge S: Serum concentrations of sIL-2R, IL-6, TGF-ß1, neopterin, and zinc in chronic hepatitis $\mathrm{C}$ patients treated with interferon-alpha. Cytokine 11: 1076-1080, 1999.

30. Neuman MG, Benhamou JP, Malkieicz IM, Akremi R, Shear NH, Asselah T, Ibrahim A, Boyer N, Martinot-Peignoux M, JacobsonBrown P, Katz GG, Le Breton V, Le Guludec G, Suneja A and Marcellin P: Cytokines as predictors for sustained response and as markers for immunomodulation in patients with chronic hepatitis C. Clin Biochem 34: 173-182, 2001. 
31. Marinho RT, Pinto R, Santos ML, Lobos IV and Moura MC: Effects of interferon and ribavirin combination therapy on $\mathrm{CD}^{+}$ proliferation, lymphocyte activation, and Th1 and Th2 cytokine profiles in chronic hepatitis C. J Viral Hep 11: 206-216, 2004.

32. Esquivel CA, Elewaut A, Philippe J, Elewaut AE, Desombere I, Maertens G and Leroux-Roels G: Evolution of hepatitis C virusspecific $\mathrm{T}$-cell responses and cytokine production in chronic hepatitis $C$ patients treated with high doses of interferon- $\alpha$. Rev Invest Clin 54: 41-50, 2002

33. Gramenzi A, Andreone P, Loggi E, Foschi FG, Cursaro C, Margotti M and Biselli M: Cytokine profile of peripheral blood mononuclear cells from patients with different outcomes of hepatitis C virus infection. J Viral Hepat 12: 525-530, 2005.
34. Lakatos PL, Firneisz G, Rakoczy G, Selmeci L and Szalay F: Elevated serum dipeptidyl peptidase IV (CD26, EC 3.4.14.5) activity in patients with primary biliary cirrhosis. J Hepatol 30: 740,1999

35. Perner F, Gyuris T, Rakoczy G, Sarvary E, Gorog D, Szalay F, Kunos I, Szonyi L, Peterfy M and Takacs L: Dipeptidyl peptidase activity of CD26 in serum and urine as a marker of cholestasis: experimental and clinical evidence. Lab Clin Med 134: 56-57, 1999. 